\title{
Environmental and genetic factors affecting cow survival of Israeli Holsteins
}

\author{
J. I. Weller ${ }^{* 1}$ and E. Ezrał \\ *Institute of Animal Sciences, ARO, The Volcani Center, Bet Dagan 50250, Israel \\ łlsrael Cattle Breeders Association, Caesaria Industrial Park 38900, Israel
}

\begin{abstract}
The objectives were to investigate the effects of various environmental factors that may affect herd-life of Israeli Holsteins, including first-calving age and season, calving ease, number of progeny born, and service sire for first calving in complete and truncated records; and to estimate heritabilities and genetic correlations between herd-life and the other traits included in the Israeli breeding index. The basic data set consisted of 590,869 cows in milk recording herds with first freshening day between 1985 and at least 8 yr before the cutoff date of September 15, 2013. Herd-life was measured as days from first calving to culling. The phenotypic and genetic trends for herd-life were 5.7 and $16.8 \mathrm{~d} /$ yr. The genetic trend was almost linear, whereas the phenotypic trend showed 4 peaks and 3 valleys. Cows born in February and March had the shortest herdlife, whereas cows born in September had the longest herd-life. Herd-life was maximal with calving age of 23 mo, which is 1 mo less than the mean calving age, and minimal at 19 and 31 mo of calving age. Dystocia and twinning on first-parity calving reduced herd-life by approximately 180 and $120 \mathrm{~d}$, but the interaction effect increased herd-life by $140 \mathrm{~d}$. Heritability for herd-life was 0.14 . Despite the fact that the service sire effect was significant in the fixed model analysis, service sire effect accounted for $<0.05 \%$ of the total variance. In the analysis of 1,431,938 truncated records, the effects of dystocia and twinning rate were very similar but less than $50 \%$ of the effects found in the analysis of complete records. Pregnancy at the truncation date increased expected herd-life by $432 \mathrm{~d}$. The correlation between actual herd-life and predicted herd-life based on truncated records was 0.44 . Genetic correlations between the truncated records and actual herd-life were 0.75 for records truncated after 6 mo but approached unity for records truncated after 3 yr. The genetic correlations of herd-life with first-parity milk, fat, and protein production, somatic cell score (SCS), and fe-
\end{abstract}

Received July 22, 2014.

Accepted September 16, 2014.

${ }^{1}$ Corresponding author: joel.weller@mail.huji.ac.il male fertility were all positive, except for SCS, in which negative values are economically favorable. The highest correlations with herd-life in absolute value were with female fertility and SCS.

Key words: dairy cattle, cow survival, longevity, heritability, Israeli Holstein

\section{INTRODUCTION}

Longevity, or herd-life (HL), is of major economic importance in dairy cattle (VanRaden and Wiggans, 1995). In the past, direct selection for cow survival has been limited. First, actual measurement of HL is only possible after the cow has been culled, and most selection decisions, especially with respect to bulls, are made long before the last of their daughters are culled. Second, although there is disagreement as to the optimal measure of cow survival, all measures have relatively low heritability (Vollema and Groen 1996), and unlike milk yield traits, there is only one record per cow. Two approaches have been suggested to include HL in a breeding program: inclusion of a direct measure of HL in the selection index (VanRaden and Wiggans 1995) or selection for other traits that are correlated with HL but have higher heritability and are expressed earlier (Vollema and Groen, 1997).

Three basic strategies have been suggested to evaluate HL for live cows. First, cow survival to a specific age can be analyzed as a binary trait using either linear or threshold models (Harris et al., 1992; Jairath et al., 1998; Vollema and Groen, 1998). Second, VanRaden and Klaaskate (1993) proposed estimating life expectancy of live cows and including these records in a linear model analysis. Estimates based on incomplete data are regressed toward the mean, and therefore have lower heritability and variance than do complete records (VanRaden et al., 1991; Settar and Weller, 1999). In the method first proposed by Weller (1988), incomplete records are multiplied by a factor to bring all records to an equal genetic variance. Because the incomplete records have lower heritability, this strategy results in greater residual variance for the incomplete records. The records are then weighted in the mixed model equations according to their residual variances. 
The third method is survival analysis or consideration of cows still alive as censored records (Vukasinovic et al., 1997; Vollema and Groen, 1998).

Numerous suggestions have been made for a definition of the longevity trait, based chiefly on either the number of parities or the actual length of HL (Vollema and Groen, 1996). VanRaden and Klaaskate (1993) evaluated months in milk up to a maximum of 84 mo but counted only a maximum of 10 mo per lactation, because records $>305 \mathrm{~d}$ are not stored. Because genetic differences for milk yield have a major effect on direct measures of survival, many studies have proposed analyzing "functional HL," which is generally computed as HL adjusted for milk yield (Dekkers, 1993; Vollema and Groen, 1996, 1998; Jairath et al., 1998). This trait accounts only for culling that is due to causes other than milk yield. The problem of double counting of production in a selection index that includes both milk yield and uncorrected HL correlated with yield can also be handled by computing appropriate economic values for these traits (VanRaden and Wiggans, 1995). Analyzing HL adjusted for yield is problematic because selection goals change over time. Until 1980, milk production was the main trait in most selection indices, whereas milk production has a zero or negative value in most current selection indices. Furthermore, the relative weight of secondary traits in most selection indices has increased over time (Miglior et al., 2005). Changes in the Israeli selection index from 1985 through 2004 are given in Table 1.

Settar and Weller (1999) studied the effect of incorporating data on pregnancy, days open (DO), and protein yields in the computation of expected HL. They derived adjustment factors from variance components for complete and incomplete HL records estimated by a multitrait animal model analysis with records truncated at different lengths considered as correlated traits. Herd-life was included in the index in 2004.

The objectives of the current study were to investigate the effects of additional factors that may affect HL, including first-calving age and season, calving ease, number of progeny born, and service sire for first calv- ing in complete and truncated records, and to estimate genetic correlations between HL and the other traits included in the Israeli breeding index. Accounting for these effects should increase the heritability of HL, resulting in more accurate genetic evaluations, especially for young bulls and cows.

\section{MATERIALS AND METHODS}

The basic data set consisted of Israeli Holstein cows in milk recording herds with first freshening day between 1985 and at least 8 yr before the cut-off date of September 15, 2013. Herd-life was measured as days from first calving to culling. For cows not culled within $8 \mathrm{yr}$ of freshening, HL was assumed to be 2,922 d. For each cow that left the herd, exit reason and exit type were recorded. Cows that were inseminated were checked for pregnancy $\sim 45 \mathrm{~d}$ after insemination by a veterinarian. Thus, the conception status of culled cows was known if the cow was culled more than $60 \mathrm{~d}$ after the last insemination. Cows were removed from the analysis for the following reasons:

1. If exit reason was listed as "accident."

2. If the cow was sold for export or sold to another farm, or if the farm was removed from the milk recording programs.

3. If age at first calving (AFC) was $<570 \mathrm{~d}$ or $>1,000 \mathrm{~d}$.

4. If the cow was recorded as pregnant, but DO was $<20$ d.

5. If first parity freshening day was not recorded.

6. If mean calving interval was $<250 \mathrm{~d}$ or $>650 \mathrm{~d}$.

7. If any lactation lasted more than 1,000 d.

8. If sex of calf from first calving was not determined.

Two calving seasons were defined for each first-parity herd-year; freshening dates between March 16 and September 15, and between September 16 and March 15. After edits, 590,869 valid HL records remained, with 33,388 first-parity herd-year-seasons (HYS). Basic

Table 1. Changes in the Israeli selection index from 1985 through 2004

\begin{tabular}{lccccccc}
\hline & \multicolumn{7}{c}{ Index coefficient by year of index change } \\
\cline { 2 - 7 } Trait & 1985 & 1990 & 1991 & 1996 & 2000 & 2001 & 2004 \\
\hline Milk (kg) & 0.51 & 0 & -0.274 & -0.274 & -0.274 & -0.22 & 0 \\
Fat (kg) & 14 & 0 & 6.41 & 6.41 & 6.41 & 8.5 & 6.3 \\
Protein (kg) & & 1.0 & 34.85 & 34.85 & 34.85 & 31.0 & 25.4 \\
SCS & & & & -300 & -300 & -300 & -300 \\
Fertility (\%) & & & & & 26.0 & 26.0 & 26.0 \\
Herd-life (d) & & & & & & 0.6 \\
\hline
\end{tabular}


Table 2. Basic statistics of the traits analyzed

\begin{tabular}{|c|c|c|c|c|}
\hline Model $^{1}$ & Trait & No. of records & Mean & $\mathrm{SD}$ \\
\hline \multirow[t]{2}{*}[1]{} & Herd-life (d) & 590,869 & 1,038 & 736 \\
\hline & Age at first calving (d) & 590,869 & 741 & 52 \\
\hline \multirow[t]{5}{*}[7]{} & Milk (kg) & 183,461 & 10,786 & 1,878 \\
\hline & Fat (kg) & 183,461 & 373 & 69 \\
\hline & Protein $(\mathrm{kg})$ & 183,461 & 333 & 55 \\
\hline & $\mathrm{SCS}^{2}$ & 183,461 & 5.01 & 1.14 \\
\hline & Female fertility ${ }^{3}(\%)$ & 183,461 & 51.3 & 34.9 \\
\hline
\end{tabular}

statistics of HL and AFC are given in Table 2. Mean AFC was slightly over $2 \mathrm{yr}$, and mean HL was $2.84 \mathrm{yr}$. Genetic evaluations for the entire population were computed by the method of Settar and Weller (1999), and genetic trend was computed as the regression of EBV for HL on birthdate. Similarly, the phenotypic trend was estimated as the regression of HL on birthdate.

Seven statistical models were analyzed. The number of records and levels of effect for the models analyzed are given in Table 3. Model [1] included the effects of HYS, dystocia, and twinning status for first calving, AFC in days, and calving month. The analysis was by PROC GLM of SAS (SAS Institute, 2008) with HYS absorbed and all factors considered fixed. The effect of AFC was assumed continuous, and all other effects were class effects. Linear, quadratic, and cubic effects of AFC - $570 \mathrm{~d}$ were included in the model. Both dystocia and twinning status were scored dichotomously, and the interaction effect was included in the model. The frequencies of first-parity dystocia and twinning in the Model [1] analysis are given in Table 4; the data set included $7.5 \%$ dystocia and $1 \%$ twin births. The frequency of twin births with dystocia (707) was 50\% higher than expected by independent association. Thus, the hypothesis of independent association was rejected $(P<0.001)$.

Model [1] was modified to include only cows with HL of at least $30 \mathrm{~d}$, to exclude cows that might have died as a direct result of first calving; this model was denoted Model [2]. Model [3] included the same factors as in the first 2 models, but without any limitation on the length of HL and with the addition of the sire of calf for the first-parity calving. Bulls that sired fewer than 100 calves were deleted from the analysis. Thus, this model included the effect of 219 sires of calves, for 581,195 cow records.

Herd-life was also analyzed by using the MTC REML program (Misztal et al., 1995), including the effects of dystocia, twinning status, sire of first-parity calf, and an additive genetic effect. Similar to Model [2], only cows with HL of at least $30 \mathrm{~d}$ were included, and the analysis included only cows with first-calving dates between 1997 and 2004. In this model, Model [4], all known parents and grandparents of cows with HL records were included in the analyses. Thus, this data set still included nearly 400,000 equations, which was near the limit of the available software. Two groups were defined for individuals without parents included in the data set, one for males and one for females. In the REML analysis, the effect of sire of calf was considered random. Heritability was estimated as the ratio of the additive genetic effect to the sum of the additive genetic and random effects.

In addition, extension factors to predict HL for cows that have not yet been culled were computed, similar to the method of Settar and Weller (1999). Records were truncated at one-half-year intervals, beginning 6 mo after first calving up to 4 yr after first calving. From 4 through 7 yr after first calving, records were censored at 1-yr intervals. For computation of extension factors, only cows still in the herd at the truncation date were included in the analysis, but each cow could have generated up to 11 records, for a total of 1,431,938 records in the analysis. Various models were tested for estimation of days remaining to culling (RHL) by PROC GLM. After removing factors without significant effects, extension factors were estimated using the following model, denoted Model [5]:

$$
\begin{gathered}
\mathrm{RHL}=\mathrm{CHL}+\mathrm{CHL}^{2}+\mathrm{DC}+\mathrm{TWIN}+\mathrm{DC} \times \mathrm{TWIN} \\
+\mathrm{LAC}+\mathrm{DR}+\mathrm{DR}^{2}+\mathrm{PREG}+\mathrm{DO}+\mathrm{DO}^{2} \\
+\mathrm{DO}^{3}+\mathrm{CHL} \times \mathrm{DO}+\mathrm{DRY}+\mathrm{PRO}+\mathrm{PRO}^{2}
\end{gathered}
$$

where $\mathrm{CHL}=$ days from first calving to truncation date; $\mathrm{DC}=$ dystocia status for first-parity calving (calving was scored as either "normal" or "difficult"); TWIN = number of calves born at first-parity calving (records of cows with more than 2 calves are very rare and were discarded); $\mathrm{DC} \times \mathrm{TWIN}=$ the interaction between 
Table 3. Number of records and levels of effect for the models analyzed

\begin{tabular}{|c|c|c|c|}
\hline Model & No. of records & Effect & No. of levels \\
\hline \multirow{6}{*}[1]{, fixed } & \multirow{6}{*}{590,869} & Herd-year-season & 33,388 \\
\hline & & First parity freshening month & 12 \\
\hline & & Dystocia & 2 \\
\hline & & Twinning & 2 \\
\hline & & Dystocia $\times$ twinning & 4 \\
\hline & & Age at first calving -570 & Continuous \\
\hline \multirow[t]{6}{*}[2]{, fixed $^{1}$} & \multirow[t]{6}{*}{568,798} & Herd-year-season & 33,292 \\
\hline & & First parity freshening month & 12 \\
\hline & & Dystocia & 2 \\
\hline & & Twinning & 2 \\
\hline & & Dystocia $\times$ twinning & 4 \\
\hline & & Age at first calving -570 & Continuous \\
\hline \multirow[t]{7}{*}[3]{, fixed } & \multirow[t]{7}{*}{581,195} & Herd-year-season & 33,334 \\
\hline & & Sire of calf & 219 \\
\hline & & First parity freshening month & 12 \\
\hline & & Dystocia & 2 \\
\hline & & Twinning & 2 \\
\hline & & Dystocia $\times$ twinning & 4 \\
\hline & & Age at first calving -570 & Continuous \\
\hline \multirow{6}{*}[4]{, $\mathrm{REML}^{1}$} & \multirow[t]{6}{*}{245,393} & Herd-year-season & 15,373 \\
\hline & & Animals (including ancestors) & 376,830 \\
\hline & & Genetic groups & 2 \\
\hline & & Sire of calf & 156 \\
\hline & & Dystocia & 2 \\
\hline & & Twinning & 2 \\
\hline \multirow[t]{10}{*}{ [5], fixed } & \multirow[t]{10}{*}{$1,431,938$} & Herd-year-season & 27,198 \\
\hline & & Lactation & 7 \\
\hline & & Dystocia & 2 \\
\hline & & Twinning & 2 \\
\hline & & Pregnancy status & 2 \\
\hline & & Days from first calving to truncation & Continuous \\
\hline & & Days pregnant & Continuous \\
\hline & & Days open & Continuous \\
\hline & & Dry days & Continuous \\
\hline & & Protein production deviation from annual mean & Continuous \\
\hline \multirow[t]{6}{*}{ [6], REML } & \multirow[t]{6}{*}{151,399} & Herd-year-season & 14728 \\
\hline & & Animals (including ancestors) & 278,056 \\
\hline & & Genetic groups & 2 \\
\hline & & Dystocia & 2 \\
\hline & & Twinning & 2 \\
\hline & & Number of traits & 12 \\
\hline \multirow{7}{*}{ [7], REML } & \multirow[t]{7}{*}{183,461} & Herd-year-season & 16,266 \\
\hline & & Animals (including ancestors) & 317,003 \\
\hline & & Genetic groups & 2 \\
\hline & & Dystocia & 2 \\
\hline & & Twinning & 2 \\
\hline & & Age at first calving in months & 13 \\
\hline & & Number of traits & 6 \\
\hline
\end{tabular}

${ }^{1}$ Cows with herd-life $<30 \mathrm{~d}$ were deleted.

DC and TWIN; LAC = lactation number at truncation date; $\mathrm{DR}=$ days pregnant at truncation date and zero for open cows; PREG = pregnancy status of the cow at the truncation date; $\mathrm{DO}=$ days open at truncation date and DIM for cows that were not pregnant by the truncation date; $\mathrm{CHL} \times \mathrm{DO}=$ the interaction between CHL and DO; DRY = days dry for dry cows at the truncation date and zero for lactating cows; and PRO

Table 4. Frequency of first-parity dystocia and twinning rate in the Model [1] analysis

\begin{tabular}{lccc}
\hline & \multicolumn{2}{c}{ Number of calves born } & \\
\cline { 2 - 3 } Calving type & 1 & 2 & Total (\%) \\
\hline Difficult & 43,951 & 707 & $44,658(7.56)$ \\
Normal & 540,906 & 5,305 & $546,211(92.44)$ \\
Total $(\%)$ & $584,857(98.98)$ & $6,012(1.02)$ & 590,869 \\
\hline
\end{tabular}


$=$ the difference between estimated lactation protein of the last lactation before the truncation date and annual mean protein production for the complete Israeli Holstein population for the calendar year of the truncated lactation.

Based on the results of this model, expected HL was computed as CHL + predicted RHL for each truncated recorded. Heritabilities and genetic correlations among the 11 classes of truncated records and the complete records were computed by the MTC REML program. This analysis, denoted Model [6], included 151,399 cows with birthdates since January 1, 1995, and first freshening dates before January 1, 2005. This data set was limited to data from cows born during a period of $\sim 8 \mathrm{yr}$, due to software limitations in the joint analysis of 12 traits. For cows that were culled before the truncation date, actual days of HL were included in the analysis. As in the previous REML analyses, all known parents and grandparents of cows with records were included in the analysis, and 2 groups were determined for animals with parents not recorded in the data set.

The final analysis, denoted Model [7], included cows with birthdates beginning January 1, 1994, and first calving dates at least 8 yr before September 15, 2013. This REML analysis computed variance and covariance components for HL, first-parity milk, fat, and protein production, SCS, and female fertility. Female fertility was computed as the inverse of the number of inseminations to conception (Weller and Ezra, 1997). For cows that were culled before verification of conception, the expected number of inseminations to conception was computed. Only cows inseminated at least once had valid records for fertility. This analysis included 183,461 cows with valid records for all 7 traits, and all known parents and grandparents. As in the other REML analyses, 2 genetic groups were defined. All the traits other than HL were adjusted for environmental effects including age and month of calving and DO, as described previously (Weller and Ezra, 1997, 2004; Weller et al., 2006).

\section{RESULTS AND DISCUSSION}

The phenotypic and genetic means of HL by birth year for model 1 are given in Figure 1. The phenotypic and genetic trends of HL were 5.7 and $16.8 \mathrm{~d} / \mathrm{yr}$, respectively. The genetic trend was nearly linear, whereas the phenotypic trend showed 4 peaks and 3 valleys. Because HL was added to the Israeli selection index in 2004, the genetic trend over the period analyzed was not affected by inclusion of HL in the selection index. The phenotypic changes in HL over time are chiefly due to changes in milk prices for production above quota.
In Israel, each farm has a production quota and prices are fixed by law. Milk prices for production within the quota are very stable, whereas prices for production above quota can vary considerably and have a dramatic effect on culling policy. Similarly, production per cow can vary due to environmental factors, such as temperature and rainfall, which can have a major effect on culling policy.

All factors included in the fixed models were significant at $P<0.001$. Effects of first-parity freshening month and age, dystocia, and twinning rate in Models [1] through [3] are given in Table 5. Coefficients of determination were $\sim 0.14$ for all 3 models. Cows freshening in February and March had the shortest HL, whereas those freshening in September had the longest HL. This is not surprising, considering that the hot summer is the main environmental stress factor in Israel, and first-parity cows freshening in these months will come into peak production in the summer. The difference was $\sim 80$ d. Herd-life means by AFC in months and predicted herd-life as a function of AFC for Model [1] are plotted in Figure 2. We observed good correspondence between the actual and predicted values. The linear and cubic effects were positive, and the quadratic effect was negative. Maximum HL was at AFC of 23 mo, which was 1 mo less than mean AFC. Herd-life was minimal at 19 and 31 mo AFC. However, only 166 cows had AFC $<20$ mo, and only 355 cows had AFC $>32$ mo. The difference between HL for cows with mean AFC of 23 and 19 mo was $260 \mathrm{~d}$. If cows with $<30 \mathrm{~d}$ HL were deleted (Model [2]), the effects for AFC were lowered by approximately one-fourth. Early insemination of virgin calves increases frequency of dystocia and calf mortality (Weller and Gianola, 1989) and results in reduced first-parity milk production (Ezra et al., 1987). Further study is needed to determine the optimum age for first insemination of virgin calves accounting for all of these factors.

In Model [1], the effects of dystocia and twinning reduced HL by $\sim 180$ and $120 \mathrm{~d}$, respectively, but the interaction effect increased HL by $140 \mathrm{~d}$. That is, for cows with both twins and dystocia, HL was reduced by only $160 \mathrm{~d}$, instead of $300 \mathrm{~d}$, as would be expected if the effects of these 2 factors were additive. Although only 707 cows ( $0.12 \%$ of all cows) had both dystocia and twins on first parity, the standard error of the interaction was 29.1 d. Although the effects in Model [3], which included the effect of service sire, were nearly the same, the effects in Model [2] were lower for both the main effects and the interaction. Thus, a major portion of the effects for dystocia and twinning rate is due to cows culled within the first 30 DIM. We observed differences of $>260 \mathrm{~d}$ between service sires with the highest and lowest effects on HL. 


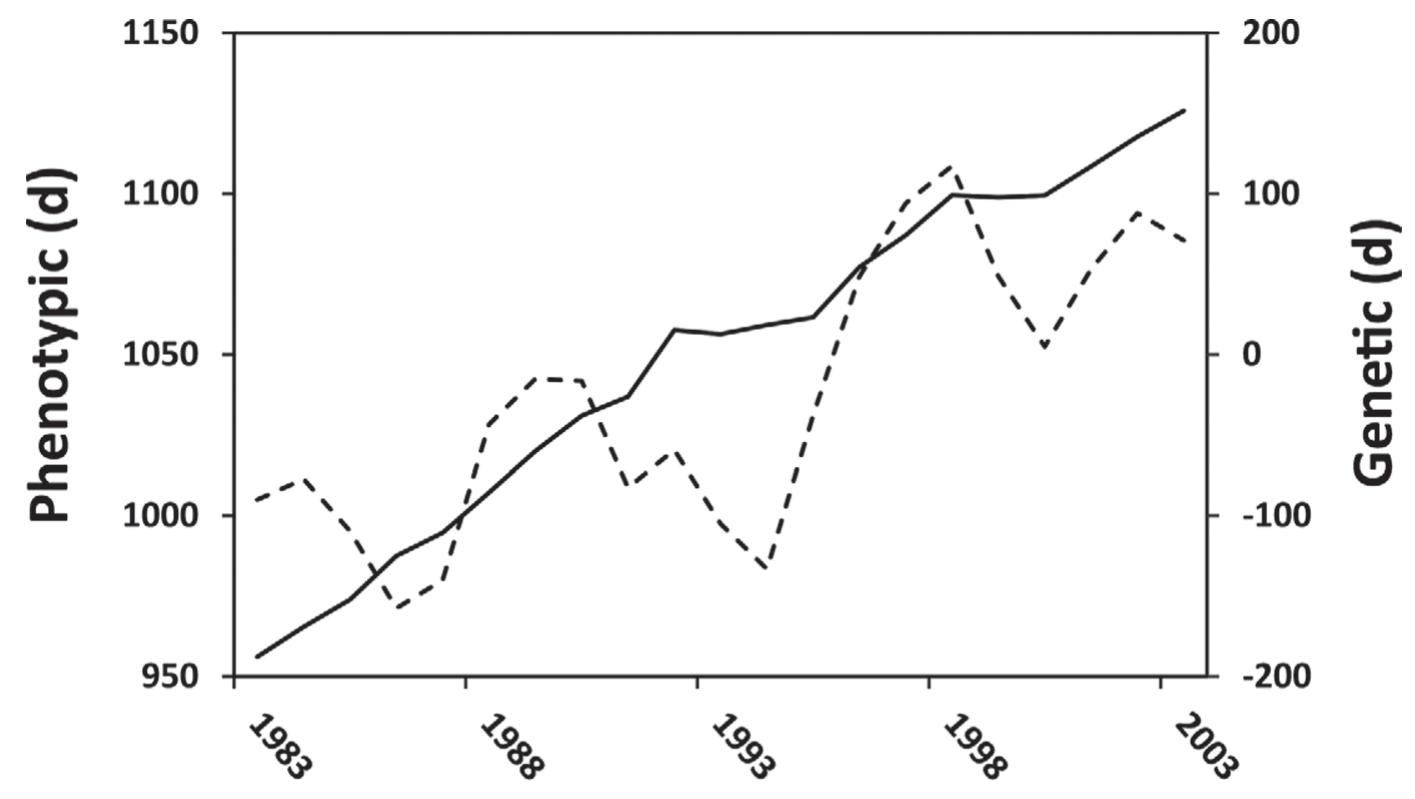

Birth Year

Figure 1. Phenotypic (- - ) and genetic (-) means of herd-life by birth year.

Variance components for the REML analysis of Model [4] are given in Table 6. Heritability after correction for the fixed effects included in the model was nearly 0.14 , which is the same as the previous estimate for HL in this population (Settar and Weller, 1999), slightly higher than for US Guernseys (Cruickshank et al., 2002) but considerably higher than for US Holsteins (VanRaden et al., 2006). Thus, accounting for the ad- ditional factors included in the model did not measurably increase the heritability. Despite the fact that the service sire effect was significant in Model [3] and that relatively large differences were found among sires, the service sire effect accounted for $<0.05 \%$ of the total variance.

The effects of the factors included in Model [5] on RHL, based on the analysis of the truncated records,

Table 5. Effects of first-parity freshening month and age, dystocia, and twinning rate on herd-life in Models [1] through [3]

\begin{tabular}{|c|c|c|c|c|}
\hline \multirow[b]{2}{*}{ Factor } & \multirow[b]{2}{*}{ Level } & \multicolumn{3}{|c|}{ Model } \\
\hline & & {$[1]$} & {$[2]$} & {$[3]$} \\
\hline \multirow[t]{11}{*}{ Calving month ${ }^{1}$} & 1 & -27.26 & -22.82 & -26.89 \\
\hline & 2 & -48.79 & -42.84 & -49.63 \\
\hline & 3 & -48.15 & -46.58 & -48.58 \\
\hline & 4 & -38.56 & -40.30 & -40.77 \\
\hline & 5 & -28.84 & -31.37 & -29.53 \\
\hline & 6 & -16.54 & -19.71 & -16.83 \\
\hline & 7 & 5.43 & 4.33 & 6.18 \\
\hline & 8 & 12.78 & 14.81 & 13.63 \\
\hline & 9 & 28.73 & 27.02 & 29.09 \\
\hline & 10 & 27.16 & 26.32 & 27.41 \\
\hline & 11 & 25.66 & 24.72 & 26.54 \\
\hline \multirow[t]{3}{*}{ Calving age $-570(\mathrm{~d})$} & Linear & 4.03 & 3.19 & 4.07 \\
\hline & Quadratic & -0.0201 & -0.0165 & -0.0202 \\
\hline & Cubic & 0.000026 & 0.000021 & 0.000026 \\
\hline Dystocia $^{2}$ & & -177.88 & -118.54 & -176.15 \\
\hline Twinning status $^{2}$ & & -120.66 & -96.98 & -121.14 \\
\hline Dystocia $\times$ twinning status & Interaction & 140.37 & 119.68 & 140.01 \\
\hline
\end{tabular}

${ }^{1}$ Relative to December.

${ }^{2}$ Relative to normal births of single calves. 
Table 6. Variance components for Model [4]

\begin{tabular}{lc}
\hline Effect & Variance $(d)^{2}$ \\
\hline Service sire & 239 \\
Additive genetic & 68,784 \\
Residual & 425,322 \\
Heritability & 0.139 \\
\hline
\end{tabular}

are given in Table 7. The effects of dystocia and twinning rate were very similar but less than $50 \%$ of the effects found in Model [2], which required HL of at least $30 \mathrm{~d}$. The interaction effect was slightly greater than the sum of the main effects. Thus, the interaction was more pronounced for the partial records than for the complete records. The RHL was not lower for cows with twin births and dystocia compared with cows with dystocia and single births or normal twin calvings. This result is somewhat surprising, but the standard error for the interaction was $15.2 \mathrm{~d}$, so the effect is apparently real. Pregnancy at the truncation date increased RHL by 432 d, compared with 420 d found by Settar and Weller (1999). Somewhat surprisingly, the effects of all parities relative to eighth were negative. Intuitively, one would expect that cows in earlier parities should have greater days from first calving to truncation date (CHL). However, parity is strongly confounded with CHL, which is negative, as expected, with a value of $-0.24 \mathrm{~d}$ per day of CHL or $-88 \mathrm{~d}$ per year CHL. The quadratic effect was also negative, and would be of ma- jor importance for cows with $\mathrm{HL}>1,000 \mathrm{~d}$ at the time of truncation. Of all the linear effects, only PRO was positive, with a value of $3 \mathrm{~d} / \mathrm{kg}$. As noted in the Materials and Methods section, DR were only computed for cows pregnant at the time of truncation, and DRY was only computed for cows dry at the time of truncation. Over all truncated records, the correlation between actual and predicted HL was 0.44 .

Heritabilities, genetic correlations, and environmental correlations for HL with records truncated from 0.5 to 8 yr (Model [6]) are given in Table 8. For cows that were not culled before the truncation date, predicted HL was computed using the extension factors of Model [5]. Heritability increased from $8 \%$ for cows truncated after 6 mo to $13 \%$ for the complete records. The value of $13 \%$ was marginally less than the value of $14 \%$ in Model [4], which analyzed only complete HL records. Genetic correlations between the truncated records and actual HL were 0.75 for records truncated after 6 mo, but approached unity for records truncated after 3 yr. Environmental correlations were lower and only approached unity for records truncated after $6 \mathrm{yr}$.

Heritabilities and genetic and environmental correlations for HL, first-parity milk, fat, and protein production, and first-parity SCS and female fertility (Model [7]) are given in Table 9. The heritability for HL in this model was only 0.112 , but this analysis included only cows with records for all 6 traits. Somatic cell score is scored only for lactations with at least 4 valid test-day

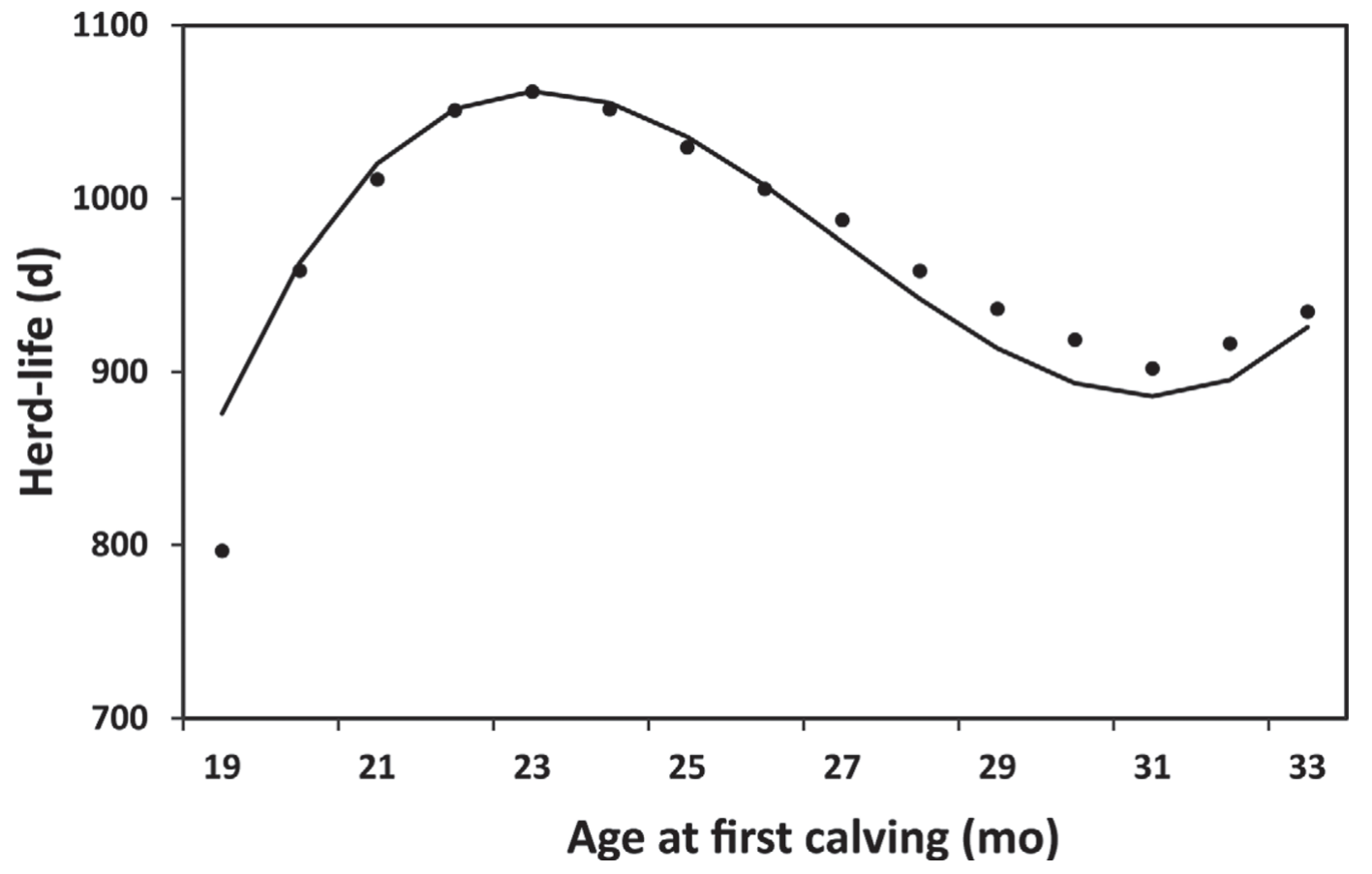

Figure 2. Herd-life ( $-=$ predicted by Model [1]; $\bullet=$ monthly means) as a function of age at first calving. 
Table 7. Effects of the factors included in Model [5] on remaining days of herd-life

\begin{tabular}{llc}
\hline Factor & Level & Effect $(\mathrm{d})$ \\
\hline Dystocia & & -43.5 \\
Twinning status & & -44.4 \\
Dystocia $\times$ twinning status & Interaction & 98.8 \\
Pregnancy status & 1 & 431.7 \\
Parity & 2 & -605.2 \\
& 3 & -642.5 \\
& 4 & -617.6 \\
& 5 & -551.2 \\
& 6 & -414.6 \\
Days from first calving to truncation & 7 & -237.5 \\
& Linear & -92.4 \\
Days pregnant & Quadratic & -0.2404 \\
& Linear & -0.00016 \\
Days open & Quadratic & -1.1007 \\
& Linear & 0.0019 \\
Days from first calving $\times$ days open & Quadratic & -2.35 \\
Days dry & Cubic & 0.0021 \\
Deviation of protein production $(\mathrm{kg})$ from annual mean & Interaction & -0.000003 \\
& Linear & 0.00074 \\
& Linear & -0.7185 \\
& Quadratic & 3.0670 \\
\end{tabular}

records, and cows must have been inseminated at least once for calculation of a fertility record (Weller and Ezra, 1997). Most cows with very low production are not inseminated. These restrictions may explain the relatively low heritabilities for the milk production traits, which were all less than 0.2 . First-parity heritabilities for SCS and fertility were similar to previous analyses of this population (Weller and Ezra, 1997, 2004).

The environmental correlations between HL and milk, fat, and protein production were only $0.143,0.143$, and 0.083 , respectively. Thus, correction of HL for any of the production traits, as several studies have proposed (Dekkers, 1993; Vollema and Groen, 1996, 1998; Jairath et al., 1998), would have only a minor effect. The genetic correlations of HL with the other 6 traits were all positive, except for SCS, in which negative values are economically favorable. The highest correlations with HL (in absolute values) were with female fertility and SCS. These correlations can explain the positive genetic trend in HL as shown in Figure 1, even though HL was only included in the selection index in 2004 . Protein, SCS, and fertility were included in the index in 1990, 1996, and 2000, respectively (Table 1).

\section{CONCLUSIONS}

The phenotypic and genetic trends for HL were 5.7 and $16.8 \mathrm{~d} / \mathrm{yr}$. The genetic trend was nearly linear, whereas the phenotypic trend showed 4 peaks and 3 valleys. Cows born in February and March had the shortest HL, whereas cows born in September had the longest HL. Herd-life was maximal at AFC of 23 mo and minimal at 19 and 31 mo AFC. Dystocia and twinning on first-parity calving reduced HL by $\sim 180$ and

Table 8. Heritabilities (on the diagonal), genetic correlations (above the diagonal), and environmental correlations (below the diagonal) for herd-life with records truncated from 0.5 to 8 yr (Model [6])

\begin{tabular}{|c|c|c|c|c|c|c|c|c|c|c|c|c|}
\hline $\begin{array}{l}\text { Truncation } \\
\text { point (yr) }\end{array}$ & 0.5 & 1 & 1.5 & 2 & 2.5 & 3 & 3.5 & 4 & 5 & 6 & 7 & 8 \\
\hline 0.5 & 0.08 & 0.97 & 0.92 & 0.89 & 0.85 & 0.83 & 0.80 & 0.79 & 0.76 & 0.75 & 0.75 & 0.75 \\
\hline 1 & 0.77 & 0.09 & 0.99 & 0.97 & 0.95 & 0.94 & 0.92 & 0.91 & 0.90 & 0.89 & 0.89 & 0.89 \\
\hline 1.5 & 0.71 & 0.80 & 0.09 & 1.00 & 0.99 & 0.98 & 0.97 & 0.96 & 0.95 & 0.95 & 0.94 & 0.94 \\
\hline 2 & 0.62 & 0.77 & 0.89 & 0.10 & 1.00 & 0.99 & 0.99 & 0.98 & 0.97 & 0.97 & 0.96 & 0.96 \\
\hline 2.5 & 0.59 & 0.73 & 0.84 & 0.92 & 0.11 & 1.00 & 1.00 & 0.99 & 0.99 & 0.99 & 0.98 & 0.98 \\
\hline 3 & 0.57 & 0.72 & 0.81 & 0.89 & 0.94 & 0.11 & 1.00 & 1.00 & 0.99 & 0.99 & 0.99 & 0.99 \\
\hline 3.5 & 0.55 & 0.71 & 0.79 & 0.87 & 0.92 & 0.96 & 0.12 & 1.00 & 1.00 & 1.00 & 1.00 & 1.00 \\
\hline 4 & 0.55 & 0.71 & 0.78 & 0.86 & 0.91 & 0.95 & 0.97 & 0.12 & 1.00 & 1.00 & 1.00 & 1.00 \\
\hline 5 & 0.54 & 0.71 & 0.77 & 0.85 & 0.89 & 0.93 & 0.95 & 0.97 & 0.13 & 1.00 & 1.00 & 1.00 \\
\hline 6 & 0.53 & 0.70 & 0.76 & 0.85 & 0.89 & 0.92 & 0.95 & 0.97 & 0.99 & 0.13 & 1.00 & 1.00 \\
\hline 7 & 0.52 & 0.70 & 0.76 & 0.84 & 0.88 & 0.92 & 0.94 & 0.96 & 0.99 & 1.00 & 0.13 & 1.00 \\
\hline 8 & 0.52 & 0.70 & 0.75 & 0.84 & 0.88 & 0.91 & 0.94 & 0.96 & 0.98 & 0.99 & 1.00 & 0.13 \\
\hline
\end{tabular}


Table 9. Heritabilities (on the diagonal), genetic correlations (above the diagonal), and environmental correlations (below the diagonal) for herd-life; first-parity milk, fat, and protein production; and first-parity SCS and female fertility (Model [7])

\begin{tabular}{lcccrrrr}
\hline & Herd-life & Milk & Fat & Protein & SCS & Fertility \\
\hline Herd-life & $\mathbf{0 . 1 1 2}$ & 0.249 & 0.240 & 0.209 & -0.407 & 0.620 \\
Milk & 0.143 & $\mathbf{0 . 1 5 7}$ & 0.310 & 0.644 & 0.059 & -0.243 \\
Fat & 0.143 & 0.749 & $\mathbf{0 . 1 8 5}$ & 0.516 & -0.067 & -0.131 \\
Protein & 0.083 & 0.916 & 0.788 & $\mathbf{0 . 1 2 6}$ & 0.119 & -0.251 \\
SCS & -0.128 & -0.012 & -0.040 & 0.006 & $\mathbf{0 . 2 5 9}$ & -0.352 \\
Fertility & 0.191 & -0.045 & -0.032 & -0.047 & -0.055 & $\mathbf{0 . 0 5 1}$ \\
\hline
\end{tabular}

$120 \mathrm{~d}$, respectively, but the interaction effect increased HL by $140 \mathrm{~d}$. Heritability for HL was 0.14 . Despite the fact that the service sire effect was significant in the fixed model analysis, service sire effect accounted for $<0.05 \%$ of the total variance. In the analysis of truncated records, the effects of dystocia and twinning rate were very similar, but less than half of the effects found in the analysis of complete records. Pregnancy at the truncation date increased expected HL by $432 \mathrm{~d}$, and the correlation between actual HL and predicted HL was 0.44. Genetic correlations between the truncated records and actual HL were 0.75 for records truncated after 6 mo but approached unity for records truncated after $3 \mathrm{yr}$. The genetic correlations of HL with firstparity milk, fat, and protein production, SCS, and female fertility were all positive, except for SCS, in which negative values are economically favorable. The highest correlations with HL in absolute value were with female fertility and SCS.

\section{ACKNOWLEDGMENTS}

This research was supported by grants from the Israel Dairy Board (Bet Dagan, Israel), the Chief Scientist of the Israeli Ministry of Agriculture and Rural Development (Bet Dagan, Israel), and Binational Agricultural Research and Development Fund (BARD) Research Project IS-4394-11R.

\section{REFERENCES}

Cruickshank, J., K. A. Weigel, M. R. Dentine, and B. W. Kirkpatrick. 2002. Indirect prediction of herd life in Guernsey dairy cattle. J. Dairy Sci. 85:1307-1313.

Dekkers, J. C. M. 1993. Theoretical basis for genetic parameters of herd life and effects on response to selection. J. Dairy Sci. $76: 1433-1443$

Ezra, E., J. I. Weller, and D. Drori. 1987. Estimation of environmental effects on milk protein content. Heker Umas 9:31-35. (In Hebrew).

Harris, B. L., A. E. Freeman, and E. Metzger. 1992. Analysis of herd life in Guernsey dairy cattle. J. Dairy Sci. 75:2008-2016.
Jairath, L., J. C. M. Dekkers, L. R. Schaeffer, Z. Liu, E. B. Burnside, and B. Kolstad. 1998. Genetic evaluation for herd life in Canada. J. Dairy Sci. 81:550-562.

Miglior, F., B. L. Muir, and B. J. Van Doormaal. 2005. Selection indices in Holstein cattle of various countries. J. Dairy Sci. 88:12551263.

Misztal, I., K. Weigel, and T. J. Lawlor. 1995. Approximation of estimates of (co)variance components with multiple-trait restricted maximum likelihood by multiple diagonalization for more than one random effect. J. Dairy Sci. 78:1862-1872.

SAS Institute. 2008. SAS/STAT Software. Release 9.2. SAS Institute Inc., Cary, NC.

Settar, P., and J. I. Weller. 1999. Genetic analysis of cow survival in the Israeli dairy cattle population. J. Dairy Sci. 82:2170-2177.

VanRaden, P. M., C. M. B. Dematawewa, R. E. Pearson, and M. E. Tooker. 2006. Productive life including all lactations and longer lactations with diminishing credits. J. Dairy Sci. 89:3213-3220.

VanRaden, P. M., and E. J. H. Klaaskate. 1993. Genetic evaluation of length of productive life including predicted longevity of live cows. J. Dairy Sci. 76:2758-2764.

VanRaden, P. M., and G. R. Wiggans. 1995. Productive life evaluations: Calculation, accuracy and economic value. J. Dairy Sci. 78:631-638.

VanRaden, P. M., G. R. Wiggans, and C. A. Ernst. 1991. Expansion of projected lactation yield to stabilize genetic variance. J. Dairy Sci. 74:4344-4349.

Vollema, A. R., and A. F. Groen. 1996. Genetic parameters of longevity traits of an upgrading population of dairy cattle. J. Dairy Sci. 79:2261-2267.

Vollema, A. R., and A. F. Groen. 1997. Genetic correlations between longevity and conformation traits in an upgrading dairy cattle population. J. Dairy Sci. 80:3006-3014.

Vollema, A. R., and A. F. Groen. 1998. A comparison of breeding value predictors for longevity using a linear model and survival analysis. J. Dairy Sci. 81:3315-3320.

Vukasinovic, N., J. Moll, and N. Kunzi. 1997. Analysis of productive life in Swiss brown cattle. J. Dairy Sci. 80:2572-2579.

Weller, J. I. 1988. Inclusion of partial lactations in genetic analysis of yield traits by differential weighting of records. J. Dairy Sci. 71:1873-1879

Weller, J. I., and E. Ezra. 1997. Genetic analysis of somatic cell concentration and female fertility of Israeli Holsteins by the individual animal model. J. Dairy Sci. 80:586-593.

Weller, J. I., and E. Ezra. 2004. Genetic analysis of the Israeli Holstein dairy cattle population for production and non-production traits with a multitrait animal model. J. Dairy Sci. 87:1519-1527.

Weller, J. I., E. Ezra, and G. Leitner. 2006. Genetic analysis of persistency in the Israeli Holstein population by the multitrait animal model. J. Dairy Sci. 89:2738-2746.

Weller, J. I., and D. Gianola. 1989. Models for genetic analysis of dystocia and calf mortality. J. Dairy Sci. 72:2633-2643. 